\title{
An unusual case of colonic mass
}

\section{Spyridon Vrakas $^{1}$ () | Panagiotis Kourkoulis $^{1}$ | Georgios Koutoufaris $^{1}$ | Kassiani Manoloudaki ${ }^{2}$ | Vasilis Xourgias ${ }^{1}$}

${ }^{1}$ Gastroenterology Department, Tzaneion General Hospital, Piraeus, Greece

${ }^{2}$ Department of Pathology, Tzaneion General Hospital, Piraeus, Greece

\section{Correspondence}

Spyridon Vrakas, Gastroenterology Department, Tzaneion General

Hospital, Zanni \& Afentouli 1, 18536

Piraeus, Greece.

Email: sbrakas@yahoo.gr

\author{
Abstract \\ Colonic metastasis due to pancreatic adenocarcinoma is extremely rare. Although \\ it is rare, colonic metastasis should be included in the differential diagnosis of co- \\ lonic mass.

\section{K E Y W O R D S} \\ colon, metastatic adenocarcinoma, pancreas
}

We report a case of colonic metastasis due to pancreatic adenocarcinoma. A 54-year-old Caucasian male attended our department due to acute-onset constipation, poor appetite, and weight loss of $7 \mathrm{~kg}$ over the last 6 months. He denied rectal bleeding. He reported a family history of colorectal cancer. Colonoscopy was performed, which revealed an infiltrative lesion in the sigmoid colon (Figure 1). Histological examination of the tissue biopsies revealed a poorly differentiated adenocarcinoma invading the muscularis mucosae and the underlying connective tissue. Immunohistochemically, the neoplasm was positive for CK7, CK19, Ca125 negative for CK20 and PSA, while there was a low level focal CDX2 expression (Figure 2). The above findings point to a possible metastasis from a pancreatic or bile duct primary neoplasm. Magnetic resonance imaging with gadolinium enhancement was performed and showed a mass measuring $4.5 \times 4.1 \mathrm{~cm}$ at the pancreatic tail invading coeliac axis (Figure 3 ). Peritoneal carcinomatosis was also suggested by the concomitant imaging findings (T4NxM1).

Given the findings of both the immunochemical and imaging workup, the carcinoma was presumed to be pancreatic in origin. Patient received chemotherapy with gemcitabine-paclitaxel and died 6 months after the diagnosis.
The retro-peritoneal location of the pancreas allows for metastatic dissemination to many organs. Most common sites include the liver, lungs, peritoneum and regional lymph nodes. Colonic metastasis of pancreatic cancer is extremely rare, with a few cases having been described previously in the literature. ${ }^{1,2}$ Metastasis is usually located

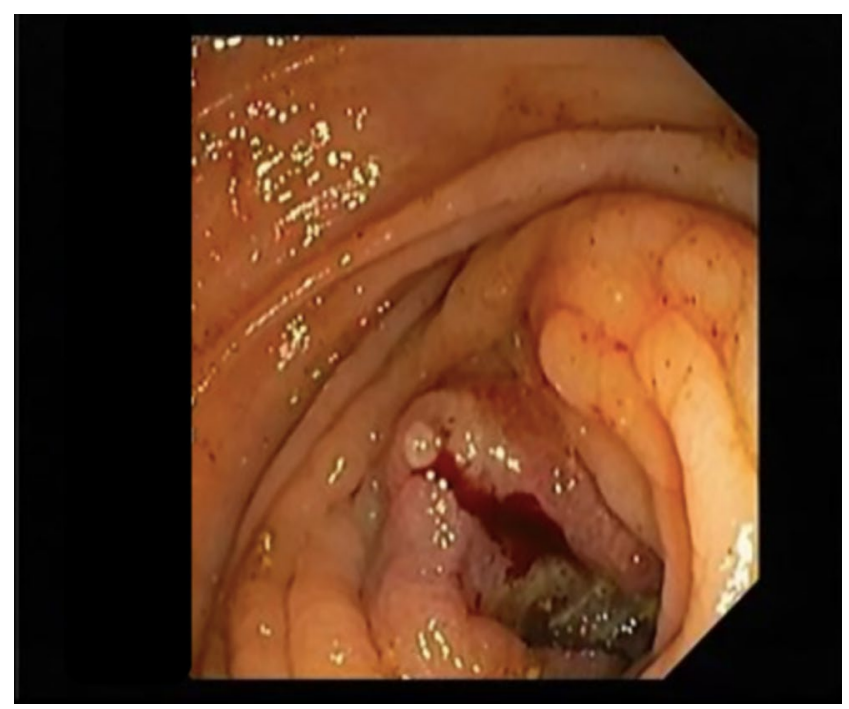

F I G U RE 1 Colonoscopy showing infiltrative lesion in the sigmoid colon 

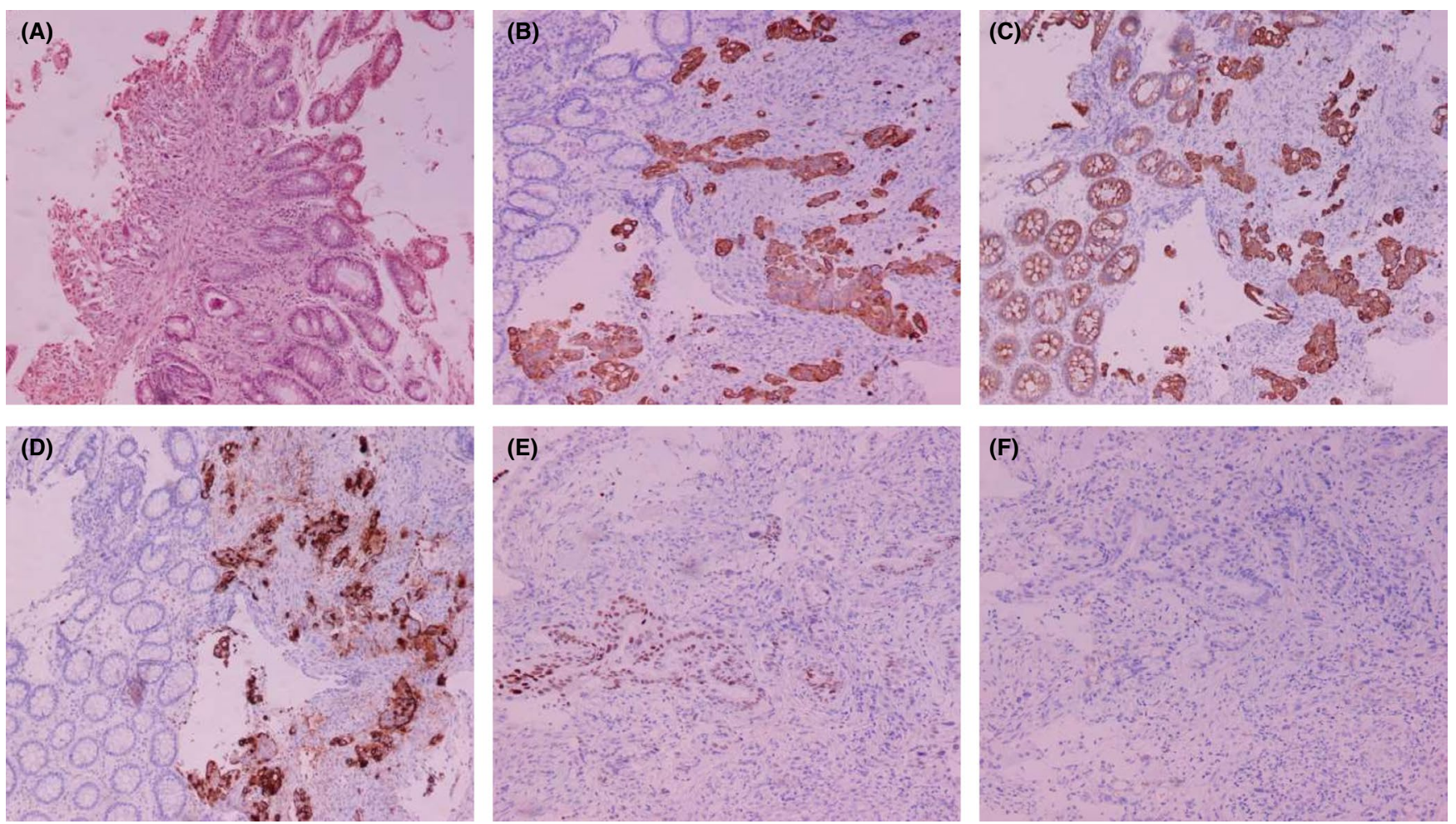

F I G U RE 2 Histological examination (A) of the colonic tumor tissue (H\&E). Immunohistochemically, the neoplasm was positive for CK7 (B), CK19 (C), Ca125 (D) negative for CK20 (F) with a low level focal CDX2 expression (E)

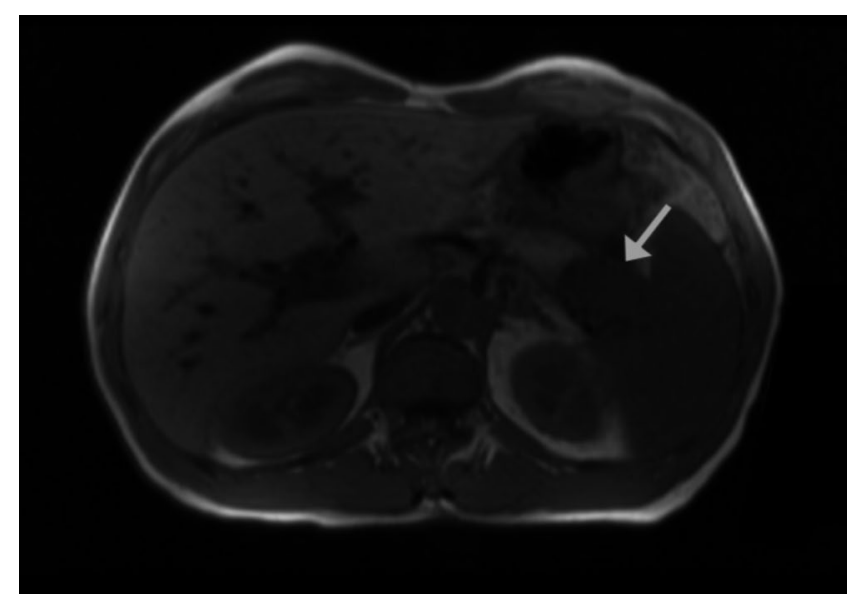

F I G U RE 3 Magnetic tomography showing a pancreatic mass $4.5 \times 4.1 \mathrm{~cm}$ diameter at the pancreatic tail

in the right colon and in the sigmoid. Colonic metastasis should be included in the differential diagnosis of a colonic mass.

\section{ACKNOWLEDGEMENTS}

Published with written consent of the patient.

\section{CONFLICT OF INTEREST}

None declared.

\section{AUTHOR CONTRIBUTIONS}

VS, KP, KG, MK, and XV contributed to the writing and approval of the final manuscript.

\section{ETHICAL APPROVAL}

Written informed consent was obtained from patient. This case report did not receive any funding. The authors have access to all source data for this case report.

\section{CONSENT}

Informed consent has been obtained from patient for the publication of this clinical image.

\section{DATA AVAILABILITY STATEMENT}

Data supporting the findings of this study are available from the corresponding author on request.

\section{ORCID}

Spyridon Vrakas (10) https://orcid.

org/0000-0003-3162-4150 


\section{REFERENCES}

1. Inada K, Shida D, Noda K, Inoue S, Warabi M, Umekita N. Metachronous colonic metastasis from pancreatic cancer seven years post-pancreatoduodenectomy. World $J$ Gastroenterol. 2013;19(10):1655-1658.

2. Bellows C, Gage T, Stark M, McCarty C, Haque S. Metastatic pancreatic carcinoma presenting as colon carcinoma. South Med J. 2009;102(7):748-750.
How to cite this article: Vrakas $\mathrm{S}$, Kourkoulis $\mathrm{P}$, Koutoufaris G, Manoloudaki K, Xourgias V. An unusual case of colonic mass. Clin Case Rep.

2021;9:e04848. https://doi.org/10.1002/ccr3.4848 